\title{
THE
}

\section{Electroless Plating of Thin Gold Films Directly onto Silicon Nitride Thin Films and into Micropores}

Julie C. Whelan

University of Rhode Island

Buddini Iroshika Karawdeniya

University of Rhode Island

Y.M. Nuwan D.Y. Bandara

University of Rhode Island

Brian D. Velleco

University of Rhode Island

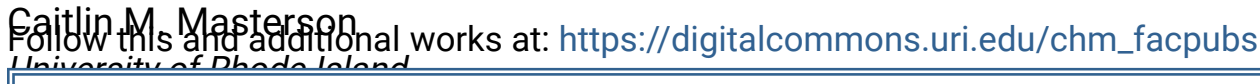

The University of Rhode Island Faculty have made this article openly available. Please let us know how Open Access to this research benefits you.

This is a pre-publication author manuscript of the final, published article.

Terms of Use

This article is made available under the terms and conditions applicable towards Open Access

Policy Articles, as set forth in our Terms of Use.

\section{Citation/Publisher Attribution}

Whelan, J C., Karawdeniya, B. I., Nuwan, Y. M., Bandara, D. Y., Velleco, B. D., Masterson C. M., \& Dwyer, J. R. (2014). Electroless Plating of Thin Gold Films Directly onto Silicon Nitride Thin Films and into Micropores. ACS Appl. Mater. Interfaces, 6(14), 10952-10957. doi: 10.1021/am501971n Available at: http://dx.doi.org/10.1021/am501971n 


\section{Authors}

Julie C. Whelan, Buddini Iroshika Karawdeniya, Y.M. Nuwan D.Y. Bandara, Brian D. Velleco, Caitlin M. Masterson, and Jason R. Dwyer

This article is available at DigitalCommons@URI: https://digitalcommons.uri.edu/chm_facpubs/92 


\section{Electroless Plating of Thin Gold Films Directly onto}

\section{Silicon Nitride Thin Films and into Micropores.}

Julie C. Whelan, Buddini Iroshika Karawdeniyat, Y.M. Nuwan D.Y. Bandarat, Brian D.

Velleco, Caitlin M. Masterson and Jason R. Dwyer*.

Final version of manuscript available at

https://pubs.acs.org/doi/abs/10.1021/am501971n

ACS Appl. Mater. Interfaces, 2014, 6 (14), pp 10952-10957

DOI: 10.1021/am501971n (Supporting information available free of charge at

https://pubs.acs.org/doi/suppl/10.1021/am501971n)

Correction available free of charge at: https://pubs.acs.org/doi/abs/10.1021/acsami.5b09596) 


\title{
Electroless Plating of Thin Gold Films Directly onto
}

\section{Silicon Nitride Thin Films and into Micropores.}

\author{
Julie C. Whelan, Buddini Iroshika Karawdeniyat, Y.M. Nuwan D.Y. Bandarat, Brian D. \\ Velleco, Caitlin M. Masterson and Jason R. Dwyer*. \\ Department of Chemistry, University of Rhode Island, 51 Lower College Road, Kingston, RI, \\ 02881, United States.
}

\begin{abstract}
A method to directly electrolessly plate silicon-rich silicon nitride with thin gold films was developed and characterized. Films with thicknesses less than $100 \mathrm{~nm}$ were grown at 3 and $10^{\circ} \mathrm{C}$ between 0.5 and 3 hours, with mean grain sizes between $\sim 20-30 \mathrm{~nm}$. The method is compatible with plating free-standing ultrathin silicon nitride membranes, and we successfully plated the interior walls of micropore arrays in $200 \mathrm{~nm}$-thick silicon nitride membranes. The method is thus amenable to coating planar, curved, and line-of-sight-obscured silicon nitride surfaces.
\end{abstract}

KEYWORDS. Electroless plating; thin gold films; silicon nitride; micropores; surface enhanced Raman spectroscopy (SERS); tin sensitization.

Thin gold films have widespread technological utility, from forming conductive elements and overlayers, to serving as a platform for chemical surface modification by molecular selfassembly $^{1}$. For gold films incorporated into conventional micro- and nanofabricated devices, silicon nitride is an appealing choice for a substrate. It is a standard nanofabrication material, 
offering, in addition, favorable inherent properties such as mechanical strength ${ }^{2-3}$, chemical resistance, and dielectric strength ${ }^{4-5}$. Silicon nitride is thus ubiquitous as a structural and functional element in nanofabricated devices where it plays a variety of roles ${ }^{2,5-8}$. Its surface chemistry, however, presents especial challenges given the complex mixture of silicon-, oxygen-, and nitrogen-bearing surface species ${ }^{5}$. The nominal surface modification of silicon nitride is frequently carried out in practice using silane-based modification of a silica layer that may itself not be well-defined ${ }^{9}$. Thus, there remains both a need and opportunity to expand the suite of approaches useful for surface functionalizing silicon nitride directly. Electroless deposition is a particularly compelling approach to film formation: deposition proceeds from solution allowing the coating of three-dimensional surfaces, including surfaces hidden from line-of-sight deposition methods; no electrochemical instrumentation is required; no electrical power must be supplied nor must the substrate be conductive; there is no need for expensive vacuum deposition equipment; and a variety of classical physicochemical parameters such as reagent composition, solution properties such as $\mathrm{pH}$ and viscosity, and temperature, are available to tune the film properties ${ }^{10-11}$. There is a wealth of familiar approaches for the electroless plating of substrates such as polymers, for example, but no established prior art for the direct metal-cation-mediated electroless plating of gold onto silicon nitride ${ }^{12-13}$. A particularly compelling sequence exists for the electroless gold plating of poly(vinylpyrrolidone)-coated polycarbonate substrates $(\mathrm{Au} / \mathrm{PVP})^{13}$ : direct sensitization of the PVP surface with $\mathrm{Sn}^{2+}$, activation by immersion in ammoniacal silver nitrate to oxidize the surface $\mathrm{Sn}^{2+}$ to $\mathrm{Sn}^{4+}$ by reducing $\mathrm{Ag}^{+}$to elemental silver (producing, also, a small amount of silver oxide), and finally gold plating by galvanic displacement of the silver with reduction of $\mathrm{Au}(\mathrm{I})$ to $\mathrm{Au}(0)$ accompanied by the oxidation of formaldehyde. Amine and carbonyl groups in the PVP layer were proposed to complex the tin 
cation during sensitization ${ }^{13}$. Extending this approach, $\mathrm{Sn}^{2+}$ has been reported to complex effectively with oxygen-rich polymer surfaces ${ }^{12}$ and with quartz and silica substrates ${ }^{10,}{ }^{14-16}$. Tin(II) sensitization has also been reported on $\mathrm{NaOH}$-roughened surfaces ${ }^{17}$, suggesting that a specific chemical interaction may not be essential ${ }^{18}$, and underscoring the utility of electroless plating for rough and high-surface-area surfaces where physical deposition is challenged ${ }^{19}$. In principle, though, a smooth silicon nitride substrate with a well-defined silica surface layer should be amenable to direct tin sensitization. Yet, electroless deposition of gold on planar silicon nitride has been limited to routes requiring the use of a silica layer with organic linkers and metal layers between the silicon nitride and gold overlayer ${ }^{18}$. In the first case, covalent attachment of an organic monolayer using silane chemistry can be beneficial for film adhesion, but adds operational complexity ${ }^{18}$ and can constrain downstream processing conditions. In the second case, the intervening layers may lend beneficial properties, or may similarly introduce compositional constraints on applications, or morphological constraints on the final gold film nanostructure. Regardless of the ability to carry out a silica-based modification, it does not eliminate the benefits of a direct functionalization of silicon nitride. We present a dramatically simplified electroless gold deposition method in which we eliminate the initial covalent attachment of an organic monolayer to the substrate, and in which we do not need to initially mask the silicon nitride surface chemistry with a silica overlayer. Our method directly sensitizes the silicon nitride substrate with a $\mathrm{Sn}^{2+}$ solution, followed by a series of metal ion treatments in which we exert control over the gold film thickness using process time and temperature. Film thicknesses ranged from 30 to $100 \mathrm{~nm}$ for deposition times from $0.5-3 \mathrm{~h}$, and temperatures of 3 and $10^{\circ} \mathrm{C}$. 
Full details of materials and preparation are provided in the Supporting Information. In brief, polished silicon-rich low-pressure chemical vapor deposited (LPCVD) silicon nitride-coated silicon wafers were cleaved into $\sim 1 \mathrm{~cm}^{2}$ chips. The chips were then electrolessly plated with gold deposited from solution as outlined in Scheme 1. Ultrasonic cleaning of the substrate ${ }^{20}$ was strictly avoided so that straightforward extension of the scheme to ultrathin silicon nitride windows would not cause window fracture ${ }^{2-3}$. Each chip was plasma-cleaned and then briefly etched in a dilute hydrofluoric acid (HF) solution to remove unwanted native silicon oxide and expose the silicon nitride surface ${ }^{4,20}$. The prepared chips were immersed in a tin(II) chloride sensitizing solution, followed by a soak in ammoniacal silver nitrate solution ${ }^{10,13}$. The chips were carefully rinsed between each step of the process. Electroless gold plating was carried out by immersing chips in $\sim 1.5-3 \mathrm{~mL}(0.75 \mathrm{~mL}$ for micropores) of sodium gold sulfite plating solution ${ }^{21}$, with gentle rocking, in a refrigerator $\left(3^{\circ} \mathrm{C}\right.$ plating $)$ or thermoelectric cooler $\left(10^{\circ} \mathrm{C}\right.$ plating). After plating for the desired time at the desired temperature, the chips were carefully rinsed, dried and then characterized. Gold film thicknesses were obtained by atomic force microscopy (AFM) measurements across an edge from the film to the substrate. Film morphology was examined by field-emission scanning electron microscopy (FE-SEM) and analyzed using a watershed analysis. Elemental analysis of the gold film was carried out by energy-dispersive x-ray spectroscopy (EDS) and by x-ray photoelectron spectroscopy (XPS). Characterization details are provided in the Supporting Information.

Scheme 1. Electroless plating of silicon nitride. The silicon nitride-coated substrates are plasmacleaned of organics and HF-etched before the surface is exposed to $\mathrm{Sn}^{2+}$ ions which are oxidized during the redox-driven deposition of an elemental silver layer. Gold plating begins with galvanic displacement of the elemental silver. 


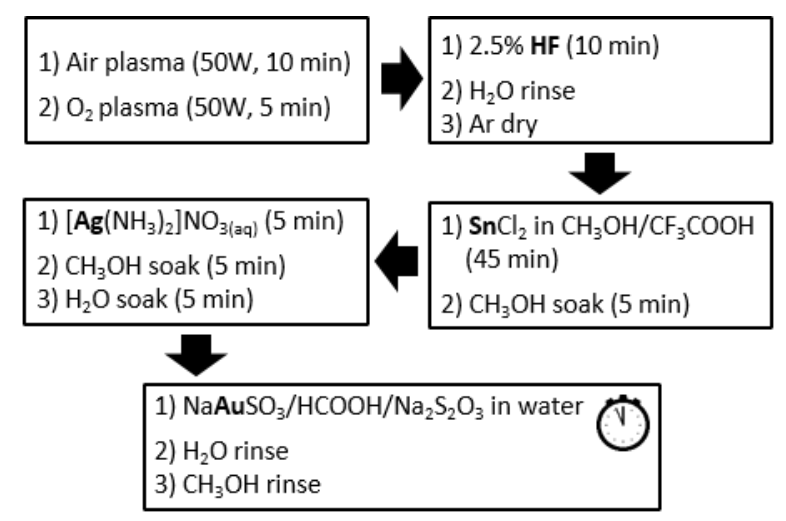

Figure 1 shows photographs of an array of silicon nitride-coated substrates subjected either strictly to the steps in Scheme 1, or to control experiment variations. Adherence to Scheme 1 produced gold films, evaluated by visual inspection, with good quality and excellent macroscopic surface coverage, and delivered these results reliably over many months of repeated trials. More detailed characterization of these films is provided below. Departures from the scheme, however, yielded generally poor or inconsistent results. We focused our attention on varying the surface preparation steps, specifically testing surface preparations that did not involve HF etching designed to remove the oxygen-containing overlayer. Tin(II) sensitization after sodium hydroxide surface roughening had been reported on silicon nitride powders of unknown stoichiometry ${ }^{5,17}$. Indeed, surface roughening to improve film adhesion is a familiar preliminary process in electroless plating ${ }^{11}$. Substituting $1,4.5$, or $9 \mathrm{M} \mathrm{NaOH}$ treatments for the HF etching of Scheme 1, however, generated only gold smudges after 3 hours of plating at $3^{\circ} \mathrm{C}$. The silicon-rich nature of our LPCVD films is a possible contributing factor to the poor plating quality after $\mathrm{NaOH}$ treatment in comparison to the published results ${ }^{17}$, given the general challenge that silicon nitride stoichiometry and available surface species-and thus functionalization opportunities ${ }^{20}$ _depend on the details of the silicon nitride synthesis ${ }^{5}$. Our use of large-area, planar substrates introduces another likely explanation: it provides a stringent test 
of film deposition quality, and easily reveals defects that may be more difficult to discern on a film coating a powder. Traditional silicon nitride surface modification schemes rely frequently on modification of a silica layer on the silicon nitride surface ${ }^{22-23}$ rather than of the silicon nitride, itself. Careful attention to the quality of the oxygen-containing surface layer can circumvent difficulties that stem from a lack of definition of this silica layer ${ }^{22}$. Holtzman and Richter used nitric acid to enrich the number of surface hydroxyl groups on silicon nitride so that they could use silane chemistry to provide an organic monolayer foundation for an overlying electrolessly deposited gold film ${ }^{18}$. While successful, the approach must contend with the acknowledged challenges of silane chemistry ${ }^{18}$ and with the persistence of the organic linker layer. Given the affinity of $\mathrm{Sn}^{2+}$ for such an oxygen-enriched silicon nitride surface, and given prior demonstrations of electroless gold plating on silica surfaces ${ }^{10}$, we replaced the HF etch in Scheme 1 with a 20 minute treatment in $10 \%(\mathrm{v} / \mathrm{v})$ nitric acid at $80^{\circ} \mathrm{C}$. The results, shown in Figure 1, were promising, with repeated, although not consistent, deposition of (visually inspected) high-quality gold films. It is likely feasible to optimize this route to routinely deposit high-quality, uniform gold films, but our goal was to develop a simple route to electrolessly plate gold directly onto silicon nitride. Treatment of silicon-rich LPCVD silicon nitride surfaces with dilute hydrofluoric acid eliminates the native oxide ${ }^{4,23}$ and leaves a H-terminated surface with $\mathrm{Si}-\mathrm{H}, \mathrm{NH}$ and $\mathrm{NH}_{2}$ moieties ${ }^{22}$. Given the appeal of this surface for surface functionalizations ${ }^{20,22}$, we tested its compatibility with tin(II)-based sensitization. Scheme 1 thus follows the plasmabased cleaning steps with an HF etch step that removes oxide and $\mathrm{H}$-terminates the surface ${ }^{22}$, and ends with the gold plating treatments ${ }^{13}$. We note that in the absence of the HF-etching step, chips would sporadically be coated with patchy gold layers, but no uniform high-quality gold films were observed on these chips even after 3 hours in the gold plating solution. 


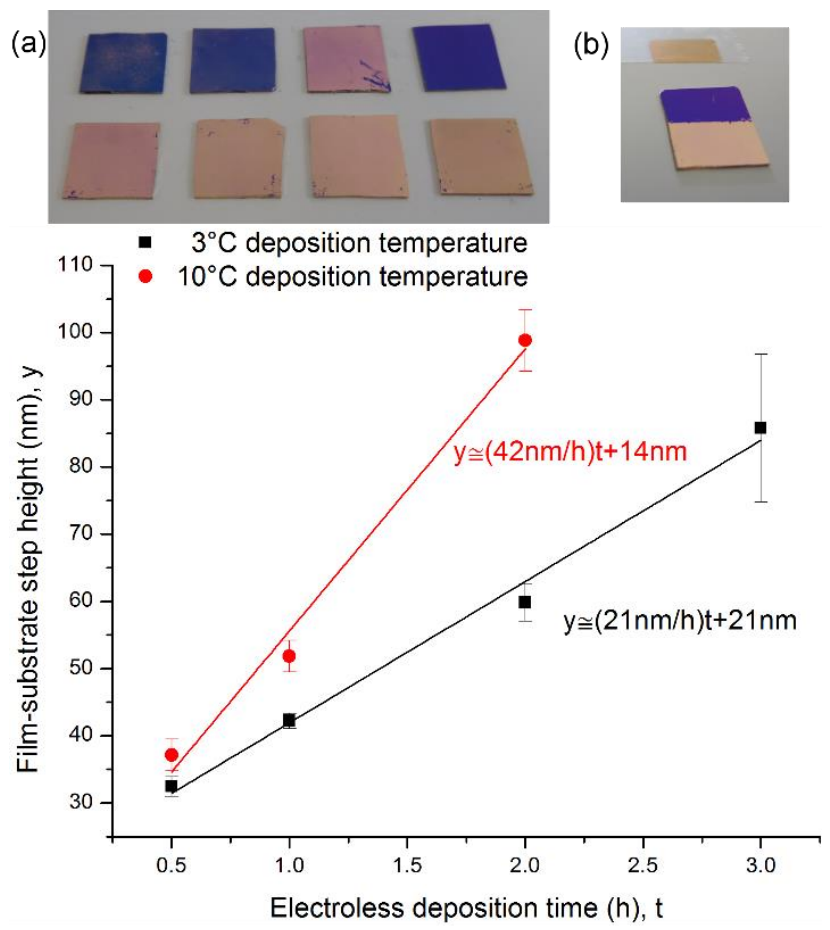

Figure 1. (a) Photograph array of plating results at $3^{\circ} \mathrm{C}$. Top row, left-to-right $-\mathrm{HF}$ etch omitted, $1 \mathrm{~h}$ plating after $\mathrm{HNO}_{3}$ preparation, $\mathrm{HNO}_{3}$ step replicate, plasma-cleaned only (subsequent steps omitted). Bottom row, left-to-right, Scheme 1 followed for plating times of 30 minutes, 1 hour, 2 hours, and 3 hours. The scratches in the film arose during handling of the chips. (b) Adhesive tape could lift most of the gold film to give an edge for (c) AFM measurements of electroless gold deposition film thickness as a function of time and temperature.

The row of visually high quality, high coverage gold films shown in Figure 1 were electrolessly plated at $3^{\circ} \mathrm{C}$ for increasing lengths of time, with strict adherence to Scheme 1 . The gold films survived extensive handling including prolonged immersion in liquids interspersed with repeated rinsing and pressurized argon-drying steps, and moreover adhered well to freestanding films that we broke deliberately for imaging (Figure 4b). Certainly in applications using gold-coated, freestanding silicon nitride membranes, consideration of membrane robustness will 
supersede gold adhesion in importance. The films could, however, be scratched with tweezers and mostly removed with adhesive tape (Figure 1b), and this afforded us the ability to perform AFM film thickness measurements. A swath of the gold film was removed and the mean difference in height between the film and the bare substrate was averaged across several representative line profiles and several independently plated chips for each plating time and temperature (see Supporting Information for details). Figure 1 plots the step height from plated film to bare substrate as a function of time: at $3^{\circ} \mathrm{C}$ a step height of $\sim 30 \mathrm{~nm}$ after 30 minutes with a linear fit yielding a $\sim 20 \mathrm{~nm} / \mathrm{h}$ deposition rate thereafter, and at $10^{\circ} \mathrm{C}$ a step height of $\sim 35 \mathrm{~nm}$ after 30 minutes with a linear fit yielding a deposition rate of $\sim 40 \mathrm{~nm} / \mathrm{h}$ thereafter. The intercept likely arises from residual silver nanoislands scattered across the substrate. Shorter plating times than those shown in Figure 1 typically produced chips with a purple-blue hue. Four-point film resistivities were measured for the films plated at $3^{\circ} \mathrm{C}$ for all the time points listed, and were in the range $\sim 3-5 \times 10^{-6} \Omega \cdot \mathrm{cm}$; thin film resistivities higher than the known bulk gold resistivity $\left(2.2 \times 10^{-6} \Omega^{\cdot} \mathrm{cm}\right)^{11}$ are not surprising ${ }^{18}$. SEM micrographs afford a further detailed view of the film structure (Figure 2). Microscopic substrate coverage was high, but not complete, after 30 minutes of plating at $3^{\circ} \mathrm{C}$, but was on par, after 30 minutes at $10^{\circ} \mathrm{C}$ and 1 hour at $3^{\circ} \mathrm{C}$, with the coverage shown in the SEM micrograph shown in Figure 2. Micrographs for both temperatures and all plating times were subjected to watershed analysis (see Supporting Information for details) and yielded area-equivalent mean grain radii from $20-30 \mathrm{~nm}$. It is clear from the SEM images, however, that the film structure is more complex than can be represented in a single equivalent grain size. There were large agglomerates on the film surface, seen also in AFM line profiles, with radii of several hundred nanometers. EDS analysis of these larger features showed them to be gold (see Supporting Information, Figure S1). Many of these outcroppings had quite 
convoluted shapes; there is the potential for quite compelling applications arising from both the regular and irregular film grain structures ${ }^{24-25}$. Indeed, the films are useful as a platform for surface-enhanced Raman spectroscopy (SERS). Figure 3 shows a demonstration spectrum of 4nitrothiophenol (NBT) taken from an electrolessly gold-coated silicon nitride substrate. Annealing of these films caused an attendant decrease in the SERS signal, and after annealing for 24 hours at $280^{\circ} \mathrm{C}$, the mean grain size had increased to nearly $50 \mathrm{~nm}$.

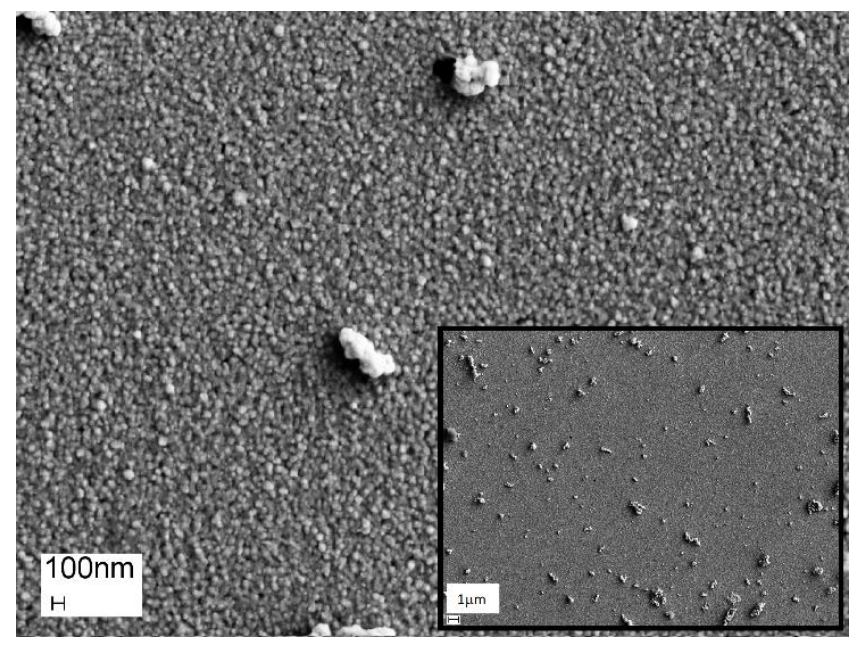

Figure 2. SEM images of a film after $2 \mathrm{~h}$ of gold plating at $3^{\circ} \mathrm{C}$. The inset is of the same film at lower magnification.

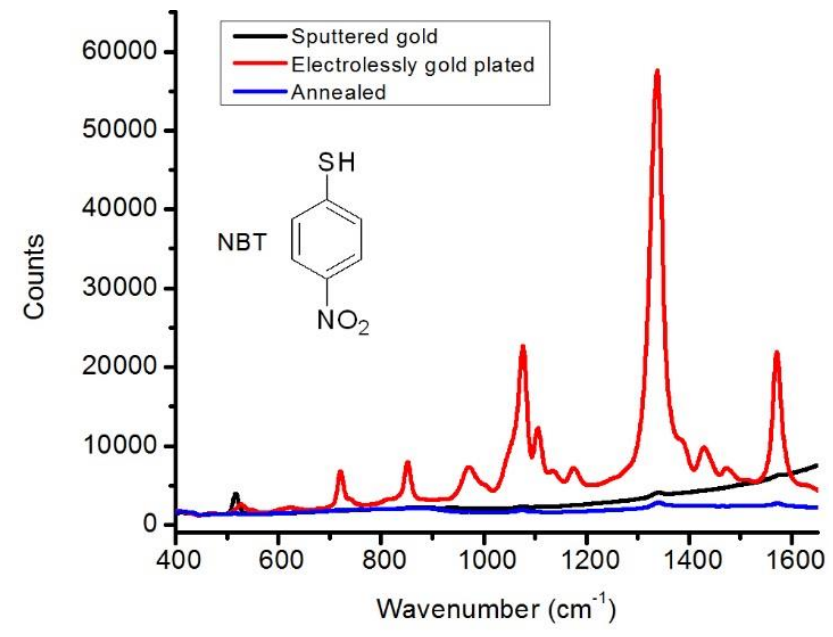


Figure 3. Measured spectra from $1 \mathrm{~cm}^{2}$ silicon nitride substrates soaked in $0.01 \mathrm{M}$ NBT for 5 minutes: from a substrate electrolessly gold-plated at $3^{\circ} \mathrm{C}$ for 3 hours (red), from the same chip plasma cleaned, annealed at $280^{\circ} \mathrm{C}$ for 20 minutes, and plasma cleaned again before NBT exposure (blue), and from a sputtered (30s) gold film (black).

While the electroless gold plating was strongly sensitive to the surface preparation of the silicon nitride, we note, for completeness, that the exposed silicon at the edges of the chips was consistently gold-plated, regardless of whether the wafer was treated with $\mathrm{HF}, \mathrm{HNO}_{3}$ or $\mathrm{NaOH}$. Polished $\sim 1 \mathrm{~cm}^{2}$ silicon chips treated according to Scheme 1 developed uniform, high-quality gold films across the surface. This result suggests that the silicon-rich nature of our silicon nitride films may contribute to the electroless plating process in Scheme 1. Candidate mechanisms for tin-sensitizing silicon nitride thus extend beyond those involving nitrogencontaining surface species ${ }^{13}$. The prospect of definitive elucidation of the mechanism, however, must be weighed in the context of clear precedent in the literature that the complexity of silicon nitride surface chemistry makes it difficult to unravel surface attachment mechanisms ${ }^{20}$. The chemical complexity of the reagents and supporting media involved in electroless plating further compounds the challenges, compared to physical deposition in vacuum or covalent attachment chemistry in solution. Nevertheless, the steps of various electroless plating approaches have a sound electrochemical basis and the method has a demonstrable outcome ${ }^{11}$. XPS spectra were recorded from silicon nitride chips after each major step of Scheme 1. Selected spectra and details of the analysis are provided in the Supporting Information (Figure S2). XPS spectra were also recorded from silicon chips for use as a guide to unravelling the overlapping contributions to the Si2p region of the silicon nitride spectra, especially. HF treatment of the oxygen-plasmacleaned silicon and silicon nitride caused a significant diminution of oxygen-related peaks at 
$\sim 104 \mathrm{eV}(\mathrm{Si} 2 \mathrm{p})$ and $\sim 533 \mathrm{eV}(\mathrm{O} 1 \mathrm{~s})$, with the first component no longer evident. These spectral features - including the residual O1s peak that could indicate surface reoxidation generating a small number of surface hydroxyl groups, but has been principally attributed to presumably surface-inaccessible bulk oxygen - are consonant with those recorded from silicon nitride substrates prepared for direct covalent chemical modification ${ }^{9,20,22}$. The tin(II) treatment steps caused an appreciable widening of the residual, post-HF-etch O1s peaks of silicon and silicon nitride. We subjected silicon and silicon nitride substrates to two control treatments at this stage of Scheme 1: in the first, we omitted the hydrofluoric acid step prior to the introduction of the tin solution, and in the second, we prepared the tin sensitizing solution without adding tin. In none of the cases was the appreciable widening of the O1s peak observed. The broad, lowamplitude $102.5 \mathrm{eV}$ Si2p peak that appeared after Scheme 1 tin-sensitization of silicon also appeared after tin-free control processing, and it suggests submonolayer oxygen coverage that can arise from aqueous processing ${ }^{23,26}$. The analogous formation of silicon oxynitride ${ }^{27-28}$ on the silicon nitride substrate would be more difficult to discern from the main Si2p peak due to spectral overlap. Tin oxidation states can be difficult to definitively identify by XPS measurement ${ }^{16,29}$, but the shifts of the best-fit $\sim 487 \mathrm{eV} \mathrm{Sn} 3 \mathrm{~d}_{5 / 2}$ peak to lower binding energy after the addition of silver(I) ions to both substrates (by $\sim 0.5 \mathrm{eV}$ for $\mathrm{SiN}_{\mathrm{x}}$ and $\sim 0.15 \mathrm{eV}$ for $\mathrm{Si}$ ), would be consistent in direction with the oxidation of $\operatorname{tin}(\mathrm{II})$. The $\operatorname{Sn} 3 \mathrm{~d}_{5 / 2}$ peaks were affected by the substrate preparation, with $\sim 0.2 \mathrm{eV}$ greater width on silicon and silicon nitride substrates that had not been treated with hydrofluoric acid, with an accompanying $\sim 0.4 \mathrm{eV}$ shift to higher binding energy on the silicon substrate. Overall, the XPS spectra suggest complex roles for oxygen and tin in the surface sensitization steps and, while the detailed mechanism of sensitization remains 
unresolved, adherence to Scheme 1 exposed the silicon-rich LPCVD silicon nitride surface for direct surface modification and yielded high-quality gold films.

In fact, in spite of complex and challenging surface chemistry, the choice of silicon nitride as a substrate opens a panoply of possible applications for consideration, and the use of a solution-based gold plating method allows us to coat surfaces that are difficult or impossible to reach by line-of-sight metal coating methods. We paid special attention in our development to be able to coat free-standing thin silicon nitride membranes. As a final demonstration of the capabilities of this method, we electrolessly gold plated micropore arrays fabricated in thin $(200 \mathrm{~nm})$ silicon nitride membranes. Figure 4 shows two representative gold-coated $2 \mu \mathrm{m}$ micropores, with the first plated into a free-standing portion of the membrane, and the second plated in a region of the silicon nitride pores overlapped with the underlying silicon support frame. Gold plating of the pore walls allows for the straightforward subsequent use of thiol chemistry for surface chemical functionalization. By choosing complementary pore dimensions and gold film thickness, either by fabricating pores with smaller initial sizes, or by increasing the plating time, this electroless plating process can also be used to physically tune the pore dimensions. This method thus provides access to surfaces that may not be accessible to line-ofsight methods, and it moreover provides control over both surface physicochemical properties and physical dimensions of surface and internal pores ${ }^{7}$. In addition, the method is well-suited for tuning and enhancing the properties and performance of thin film and pore-based devices. 


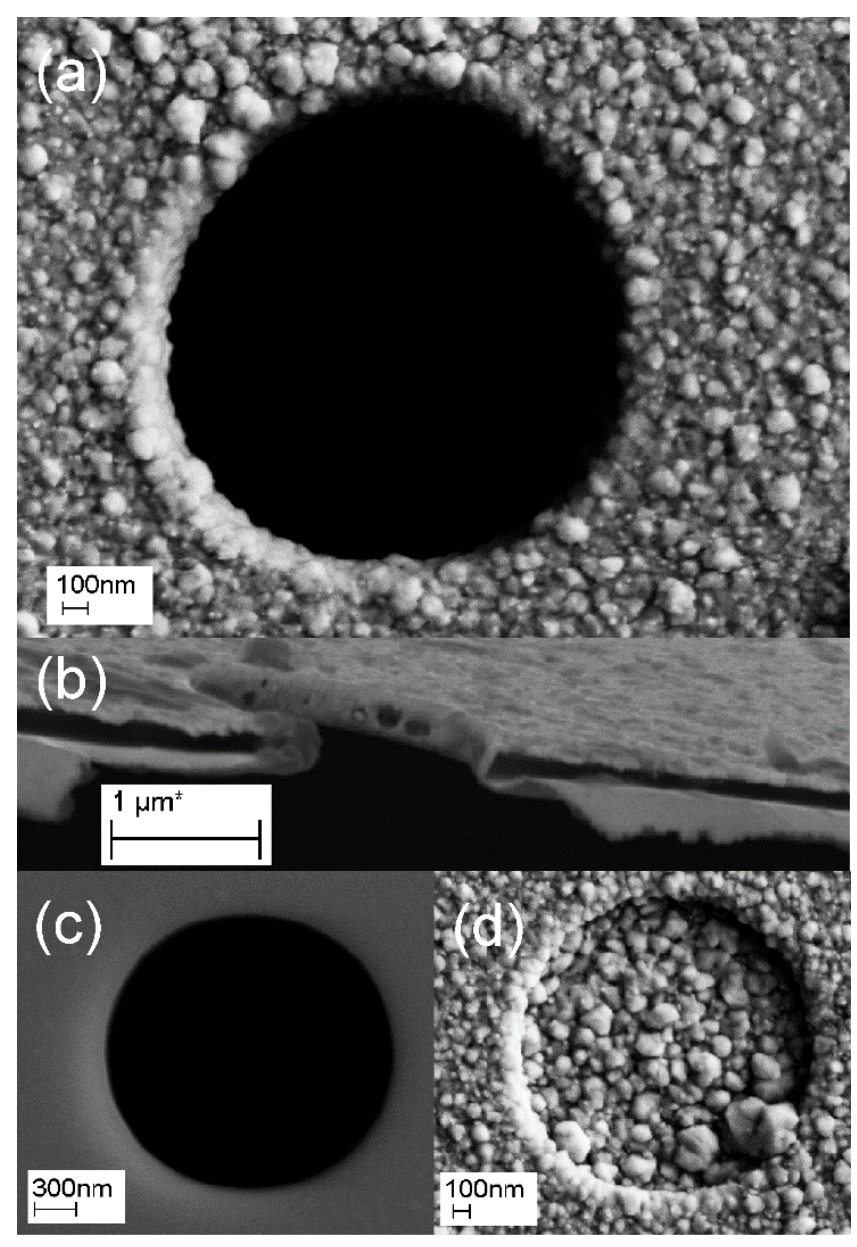

Figure 4. Gold coating can be seen to cover (a) the planar membrane and curved inner pore surface of the free-standing membrane area, with its uncoated equivalent shown in (c). A purposefully fractured membrane in (b) shows the gold coating on the micropore surface and the silicon nitride membrane (dark line) with intact gold coating. In image (d), plating also occurred on the bottom of the 200nm-deep well where it intersects with the silicon substrate.

\section{AUTHOR INFORMATION}

\section{Corresponding Author}

* E-mail: jdwyer@chm.uri.edu.

\section{Author Contributions}


All authors have given approval to the final version of the manuscript. / $\$$ These authors contributed equally.

\section{Funding Sources}

NSF CAREER award CBET-1150085, in part by NSF EPSCoR Cooperative Agreement \#IIA1330406, and by the University of Rhode Island.

\section{ACKNOWLEDGMENT}

We thank Sarah Golden for custom software used in data analysis. This research has been supported by NSF CAREER award CBET-1150085, in part by NSF EPSCoR Cooperative Agreement \#IIA-1330406, and by the University of Rhode Island.

\section{ASSOCIATED CONTENT}

Supporting Information Available: Experimental details, methods and sample characterizations. This material is available free of charge via the Internet at http://pubs.acs.org.

\section{ABBREVIATIONS}

AFM, Atomic Force Microscopy; SEM, Scanning Electron Micoscopy; FE-SEM, field-emission

SEM; EDS, energy-dispersive X-ray spectroscopy; LPCVD, low-pressure chemical vapor deposition; XPS, x-ray photoelectron spectroscopy; PVP, poly(vinylpyrrolidone); SERS; surface-enhanced Raman spectroscopy.

\section{REFERENCES}

1. Love, J. C.; Estroff, L. A.; Kriebel, J. K.; Nuzzo, R. G.; Whitesides, G. M., SelfAssembled Monolayers of Thiolates on Metals as a Form of Nanotechnology. Chem. Rev. 2005, 105, 1103-1170. 
2. Mueller, C.; Harb, M.; Dwyer, J. R.; Miller, R. J. D., Nanofluidic Cells with Controlled Pathlength and Liquid Flow for Rapid, High-Resolution In Situ Imaging with Electrons. J. Phys. Chem. Lett. 2013, 4, 2339-2347.

3. Ciarlo, D. R., Silicon Nitride Thin Windows for Biomedical Microdevices. Biomed. Microdevices 2002, 4, 63-68.

4. Williams, K. R.; Muller, R. S., Etch rates for micromachining processing. $J$. Microelectromech. Syst. 1996, 5, 256-269.

5. Habraken, F. H. P. M.; Kuiper, A. E. T., Silicon Nitride and Oxynitride Films. Mater. Sci. Eng., $R$ 1994, 12, 123-175.

6. Miles, B. N.; Ivanov, A. P.; Wilson, K. A.; Dogan, F.; Japrung, D.; Edel, J. B., Single Molecule Sensing with Solid-State Nanopores: Novel Materials, Methods, and Applications. Chem. Soc. Rev. 2013, 42, 15-28.

7. Frament, C. M.; Bandara, N.; Dwyer, J. R., Nanopore Surface Coating Delivers Nanopore Size and Shape through Conductance-Based Sizing. ACS Appl. Mater. Interfaces 2013, 5, 9330-9337.

8. Fine, D.; Grattoni, A.; Goodall, R.; Bansal, S. S.; Chiappini, C.; Hosali, S.; van de Ven, A. L.; Srinivasan, S.; Liu, X.; Godin, B.; Brousseau, L.; Yazdi, I. K.; Fernandez-Moure, J.; Tasciotti, E.; Wu, H.-J.; Hu, Y.; Klemm, S.; Ferrari, M., Silicon Micro- and Nanofabrication for Medicine. Adv. Healthcare Mater. 2013, 2, 632-666. 
9. Arafat, A.; Giesbers, M.; Rosso, M.; Sudhölter, E. J. R.; Schroën, K.; White, R. G.; Yang, L.; Linford, M. R.; Zuilhof, H., Covalent Biofunctionalization of Silicon Nitride Surfaces. Langmuir 2007, 23, 6233-6244.

10. Ahn, W.; Taylor, B.; Dall'Asen, A. G.; Roper, D. K., Electroless Gold Island Thin Films: Photoluminescence and Thermal Transformation to Nanoparticle Ensembles. Langmuir 2008, $24,4174-4184$.

11. Møller, P.; Nielsen, L. P., Advanced Surface Technology. Møller \& Nielsen APS: Denmark, 2013; Vol. 1, p 594.

12. Charbonnier, M.; Romand, M., Polymer Pretreatments for Enhanced Adhesion of Metals Deposited by the Electroless Process. Int. J. Adhes. Adhes. 2003, 23, 277-285.

13. Menon, V. P.; Martin, C. R., Fabrication and Evaluation of Nanoelectrode Ensembles. Anal. Chem. 1995, 67, 1920-1928.

14. Kobayashi, Y.; Tadaki, Y.; Nagao, D.; Konno, M., Deposition of Gold Nanoparticles on Silica Spheres by Electroless Metal Plating Technique. J. Colloid Interface Sci. 2005, 283, 601604.

15. Miller, T. C.; Holcombe, J. A., Evaluation of Electroless Gold Deposited on Porous Silica for Ligand Attachment for Metal Ion-Exchange. Anal. Chim. Acta 2002, 454, 37-44.

16. Kobayashi, Y.; Salgueiriño-Maceira, V.; Liz-Marzán, L. M., Deposition of Silver Nanoparticles on Silica Spheres by Pretreatment Steps in Electroless Plating. Chem. Mater. 2001, 13, 1630-1633. 
17. Wanbao, H.; Baolin, Z.; Hanrui, Z.; Wenlan, L., Preparation and Sintering of Ni-Coated $\mathrm{Si}_{3} \mathrm{~N}_{4}$ Composite Powders. Ceram. Int. 2005, 31, 811-815.

18. Holtzman, A.; Richter, S., Electroless Plating of Silicon Nitride Using (3-Aminopropyl) Triethoxysilane. J. Electrochem. Soc. 2008, 155, D196-D202.

19. Díaz, D. J.; Williamson, T. L.; Guo, X.; Sood, A.; Bohn, P. W., Electroless Deposition of Gold and Platinum for Metallization of the Intrapore Space in Porous Gallium Nitride. Thin Solid Films 2006, 514, 120-126.

20. Rosso, M.; Giesbers, M.; Arafat, A.; Schroën, K.; Zuilhof, H., Covalently Attached Organic Monolayers on $\mathrm{SiC}$ and $\mathrm{Si}_{x} \mathrm{~N}_{4}$ Surfaces: Formation Using UV Light at Room Temperature. Langmuir 2009, 25, 2172-2180.

21. Ko, J. W.; Koo, H. C.; Kim, D. W.; Seo, S. M.; Kang, T. J.; Kwon, Y.; Yoon, J. L.; Cheon, J. H.; Kim, Y. H.; Kim, J. J.; Park, Y. J., Electroless Gold Plating on Aluminum Patterned Chips for CMOS-Based Sensor Applications. J. Electrochem. Soc. 2010, 157, D46D49.

22. Arafat, A.; Schroën, K.; de Smet, L. C. P. M.; Sudhölter, E. J. R.; Zuilhof, H., TailorMade Functionalization of Silicon Nitride Surfaces. J. Am. Chem. Soc. 2004, 126, 8600-8601.

23. Bermudez, V. M., Wet-Chemical Treatment of $\mathrm{Si}_{3} \mathrm{~N}_{4}$ Surfaces Studied Using Infrared Attenuated Total Reflection Spectroscopy. J. Electrochem. Soc. 2005, 152, F31-F36.

24. Soleymani, L.; Fang, Z.; Lam, B.; Bin, X.; Vasilyeva, E.; Ross, A. J.; Sargent, E. H.; Kelley, S. O., Hierarchical Nanotextured Microelectrodes Overcome the Molecular Transport Barrier To Achieve Rapid, Direct Bacterial Detection. ACS Nano 2011, 5, 3360-3366. 
25. Stiles, P. L.; Dieringer, J. A.; Shah, N. C.; Van Duyne, R. P., Surface-Enhanced Raman Spectroscopy. Annu. Rev. Anal. Chem. 2008, 1, 601-626.

26. Chen, M.; Batra, I. P.; Brundle, C. R., Theoretical and Experimental Investigations of the Electronic Structure of Oxygen on Silicon. J. Vac.Sci. Technol. 1979, 16, 1216-1220.

27. Du, H.; Tressler, R. E.; Spear, K. E.; Pantano, C. G., Oxidation Studies of Crystalline CVD Silicon Nitride. J. Electrochem. Soc. 1989, 136, 1527-1536.

28. Vasquez, R. P.; Hecht, M. H.; Grunthaner, F. J.; Naiman, M. L., X-ray Photoelectron Spectroscopy Study of the Chemical Structure of Thermally Nitrided $\mathrm{SiO}_{2}$. Appl. Phys. Lett. 1984, 44, 969-971.

29. Themlin, J.-M.; Chtaïb, M.; Henrard, L.; Lambin, P.; Darville, J.; Gilles, J.-M., Characterization of Tin Oxides by X-Ray-Photoemission Spectroscopy. Phys. Rev. B: Condens. Matter Mater. Phys. 1992, 46, 2460-2466. 
TOC Image

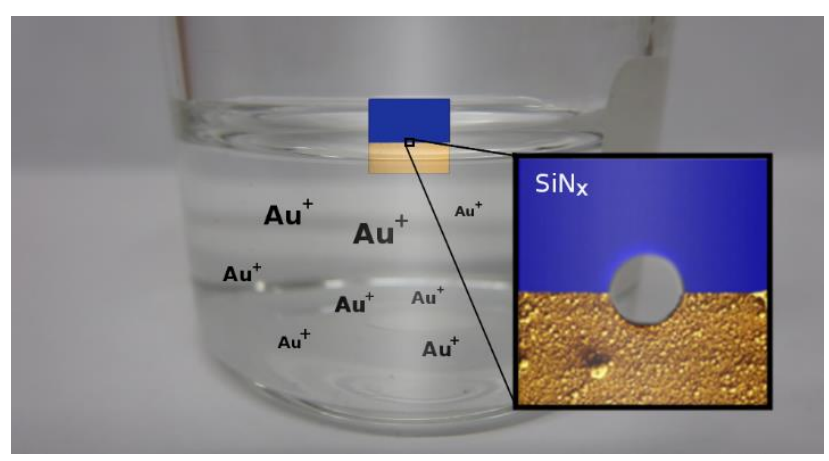


1. Love, J. C.; Estroff, L. A.; Kriebel, J. K.; Nuzzo, R. G.; Whitesides, G. M., SelfAssembled Monolayers of Thiolates on Metals as a Form of Nanotechnology. Chem. Rev. 2005, 105, 1103-1170.

2. Mueller, C.; Harb, M.; Dwyer, J. R.; Miller, R. J. D., Nanofluidic Cells with Controlled Pathlength and Liquid Flow for Rapid, High-Resolution In Situ Imaging with Electrons. J. Phys. Chem. Lett. 2013, 4, 2339-2347.

3. Ciarlo, D. R., Silicon Nitride Thin Windows for Biomedical Microdevices. Biomed. Microdevices 2002, 4, 63-68.

4. Williams, K. R.; Muller, R. S., Etch rates for micromachining processing. $J$. Microelectromech. Syst. 1996, 5, 256-269.

5. Habraken, F. H. P. M.; Kuiper, A. E. T., Silicon Nitride and Oxynitride Films. Mater. Sci. Eng., $R$ 1994, 12, 123-175.

6. Miles, B. N.; Ivanov, A. P.; Wilson, K. A.; Dogan, F.; Japrung, D.; Edel, J. B., Single Molecule Sensing with Solid-State Nanopores: Novel Materials, Methods, and Applications. Chem. Soc. Rev. 2013, 42, 15-28.

7. $\quad$ Frament, C. M.; Bandara, N.; Dwyer, J. R., Nanopore Surface Coating Delivers Nanopore Size and Shape through Conductance-Based Sizing. ACS Appl. Mater. Interfaces 2013, 5, 9330-9337.

8. Fine, D.; Grattoni, A.; Goodall, R.; Bansal, S. S.; Chiappini, C.; Hosali, S.; van de Ven, A. L.; Srinivasan, S.; Liu, X.; Godin, B.; Brousseau, L.; Yazdi, I. K.; Fernandez-Moure, J.; Tasciotti, E.; Wu, H.-J.; Hu, Y.; Klemm, S.; Ferrari, M., Silicon Micro- and Nanofabrication for Medicine. Adv. Healthcare Mater. 2013, 2, 632-666.

9. Arafat, A.; Giesbers, M.; Rosso, M.; Sudhölter, E. J. R.; Schroën, K.; White, R. G.; Yang, L.; Linford, M. R.; Zuilhof, H., Covalent Biofunctionalization of Silicon Nitride Surfaces.

Langmuir 2007, 23, 6233-6244.

10. Ahn, W.; Taylor, B.; Dall'Asen, A. G.; Roper, D. K., Electroless Gold Island Thin Films: Photoluminescence and Thermal Transformation to Nanoparticle Ensembles. Langmuir 2008, 24, 4174-4184.

11. Møller, P.; Nielsen, L. P., Advanced Surface Technology. Møller \& Nielsen APS: Denmark, 2013; Vol. 1, p 594.

12. Charbonnier, M.; Romand, M., Polymer Pretreatments for Enhanced Adhesion of Metals Deposited by the Electroless Process. Int. J. Adhes. Adhes. 2003, 23, 277-285.

13. Menon, V. P.; Martin, C. R., Fabrication and Evaluation of Nanoelectrode Ensembles. Anal. Chem. 1995, 67, 1920-1928.

14. Kobayashi, Y.; Tadaki, Y.; Nagao, D.; Konno, M., Deposition of Gold Nanoparticles on Silica Spheres by Electroless Metal Plating Technique. J. Colloid Interface Sci. 2005, 283, 601604.

15. Miller, T. C.; Holcombe, J. A., Evaluation of Electroless Gold Deposited on Porous Silica for Ligand Attachment for Metal Ion-Exchange. Anal. Chim. Acta 2002, 454, 37-44.

16. Kobayashi, Y.; Salgueiriño-Maceira, V.; Liz-Marzán, L. M., Deposition of Silver Nanoparticles on Silica Spheres by Pretreatment Steps in Electroless Plating. Chem. Mater. 2001, 13, 1630-1633.

17. Wanbao, H.; Baolin, Z.; Hanrui, Z.; Wenlan, L., Preparation and Sintering of Ni-Coated $\mathrm{Si}_{3} \mathrm{~N}_{4}$ Composite Powders. Ceram. Int. 2005, 31, 811-815. 
18. Holtzman, A.; Richter, S., Electroless Plating of Silicon Nitride Using (3-Aminopropyl) Triethoxysilane. J. Electrochem. Soc. 2008, 155, D196-D202.

19. Díaz, D. J.; Williamson, T. L.; Guo, X.; Sood, A.; Bohn, P. W., Electroless Deposition of Gold and Platinum for Metallization of the Intrapore Space in Porous Gallium Nitride. Thin Solid Films 2006, 514, 120-126.

20. Rosso, M.; Giesbers, M.; Arafat, A.; Schroën, K.; Zuilhof, H., Covalently Attached Organic Monolayers on $\mathrm{SiC}$ and $\mathrm{Si}_{\mathrm{x}} \mathrm{N}_{4}$ Surfaces: Formation Using UV Light at Room Temperature. Langmuir 2009, 25, 2172-2180.

21. Ko, J. W.; Koo, H. C.; Kim, D. W.; Seo, S. M.; Kang, T. J.; Kwon, Y.; Yoon, J. L.; Cheon, J. H.; Kim, Y. H.; Kim, J. J.; Park, Y. J., Electroless Gold Plating on Aluminum Patterned Chips for CMOS-Based Sensor Applications. J. Electrochem. Soc. 2010, 157, D46D49.

22. Arafat, A.; Schroën, K.; de Smet, L. C. P. M.; Sudhölter, E. J. R.; Zuilhof, H., TailorMade Functionalization of Silicon Nitride Surfaces. J. Am. Chem. Soc. 2004, 126, 8600-8601. 23. Bermudez, V. M., Wet-Chemical Treatment of $\mathrm{Si}_{3} \mathrm{~N}_{4}$ Surfaces Studied Using Infrared Attenuated Total Reflection Spectroscopy. J. Electrochem. Soc. 2005, 152, F31-F36.

24. Soleymani, L.; Fang, Z.; Lam, B.; Bin, X.; Vasilyeva, E.; Ross, A. J.; Sargent, E. H.; Kelley, S. O., Hierarchical Nanotextured Microelectrodes Overcome the Molecular Transport Barrier To Achieve Rapid, Direct Bacterial Detection. ACS Nano 2011, 5, 3360-3366.

25. Stiles, P. L.; Dieringer, J. A.; Shah, N. C.; Van Duyne, R. P., Surface-Enhanced Raman Spectroscopy. Annu. Rev. Anal. Chem. 2008, 1, 601-626.

26. Chen, M.; Batra, I. P.; Brundle, C. R., Theoretical and Experimental Investigations of the Electronic Structure of Oxygen on Silicon. J. Vac.Sci. Technol. 1979, 16, 1216-1220.

27. Du, H.; Tressler, R. E.; Spear, K. E.; Pantano, C. G., Oxidation Studies of Crystalline CVD Silicon Nitride. J. Electrochem. Soc. 1989, 136, 1527-1536.

28. Vasquez, R. P.; Hecht, M. H.; Grunthaner, F. J.; Naiman, M. L., X-ray Photoelectron Spectroscopy Study of the Chemical Structure of Thermally Nitrided $\mathrm{SiO}_{2}$. Appl. Phys. Lett. 1984, 44, 969-971.

29. Themlin, J.-M.; Chtaïb, M.; Henrard, L.; Lambin, P.; Darville, J.; Gilles, J.-M., Characterization of Tin Oxides by X-Ray-Photoemission Spectroscopy. Phys. Rev. B: Condens. Matter Mater. Phys. 1992, 46, 2460-2466. 